\title{
A time of transition in the Journal of Neuro-Oncology
}

\section{Jason Sheehan ${ }^{1}$}

Published online: 1 February 2018

(c) Springer Science+Business Media, LLC, part of Springer Nature 2018

\author{
"The job of the writer is to change \\ the way the reader sees the \\ world."
}

--Richard Ford, American Author;

winner of the PEN/Faulkner Award and the Pulitzer Prize for Fiction

Since its inception in 1983, the Journal of Neuro-Oncology (JNO) has been a multidisciplinary journal focusing on basic, translational, and clinical research in the field of neuro-oncology. The publication is the official one for the Tumor Section of the American Association of Neurological Surgeons (AANS) and the Congress of Neurological Surgeons (CNS). Thus, there has been a close and natural affiliation with the neurosurgical profession. However, with even a cursory review of the editorial board or the publications in any single issue, it is quite clear that JNO is comprised of diverse and multidisciplinary clinicians and scientists. This group includes many neurologists, neurosurgeons, radiation oncologists, medical oncologists, neuropathologists, neuroradiologists, and laboratory-based oncologists.

The JNO's impact factor was 2.980 in 2016. It has 364,018 downloads that same year. The journal allows for rapid publications and averaged 58 days from submission to first decision. Journal author satisfaction was $96 \%$. From the time of acceptance, online publication is often $<2$ weeks. With 15 issues published annually, the offerings in JNO are appreciable. It is also supported by an excellent publisher, Springer-Nature.

For the past decade, Dr. Linda M. Liau has served as Editor-In-Chief (EIC) for JNO. She has overseen countless journal submissions; she has tirelessly worked to improve the stature and carry on the mission of the JNO and the AANS and CNS Tumor Section. The field of neuro-oncology has indelibly changed and been appreciably advanced by her efforts. In translating Richard Ford's words to the world of medicine and science, a successful EIC helps to shape the way clinicians and scientists view their professional worlds, and Dr. Liau has certainly done just that. After 10 years as EIC and the recent assumption of the Chair of Neurosurgery position at University of California Los Angeles (UCLA), Dr. Liau has chosen to pass the baton to another. I am honored to follow in her footsteps as Editor-In-Chief for JNO. With this change, Dr. Liau will continue to serve as an Associate Editor.

Working with AANS and CNS Tumor Section leadership, the editorial board, and the journal's publishing team at Springer-Nature, we will look for opportunities to improve the journal while still adhering to its traditions and mission. The publishing world is, of course, undergoing rapid changes, and these changes can lead to valuable opportunities for JNO contributors and readers. Stay tuned as the best is yet to come for JNO.

Jason Sheehan

jsheehan@virginia.edu

1 Department of Neurological Surgery, University of Virginia, Box 800212, Charlottesville, VA 22908, USA 